www.jmscr.igmpublication.org

Impact Factor 3.79

Index Copernicus Value: 5.88

ISSN (e)-2347-176x ISSN (p) 2455-0450

crossref DOI: http://dx.doi.org/10.18535/jmscr/v4i02.48

Journal Of Medical Science And Clinical Research

IGM Publication

An official Publication of IGM Publication

\title{
Correlation between Serum Ascites Albumin Gradient and Esophageal Varices in Patients of Chronic Liver Disease
}

\author{
Authors \\ Ajeet Kumar Chaurasia ${ }^{1}$, BD Mangal $^{2}$ \\ ${ }^{1}$ Assistant Professor, Deptt of Medicine, MLN medical College Allahabad, U.P. INDIA \\ Email-ajeetkc30@gmail.com \\ ${ }^{2}$ Professor, Deptt of Medicine, GSVM Medical College Kanpur, U.P. INDIA \\ Corresponding Author \\ Dr Ajeet Kumar Chaurasia \\ Assistant Professor, Deptt of Medicine, MLN medical College, Allahabad (U.P) \\ Email-ajeetkc30@gmail.com,Mob-09935307698
}

\begin{abstract}
:
Introduction: Clinically significant portal hypertension is present in $>60 \%$ of patient with liver cirrhosis. Ideally portal hypertension should be evaluated by actually measuring portal pressure, but it is invasive procedure and involves catheterization of hepatic vein not applicable on a routine basis. Ascites and esophageal varices both are the complication of portal hypertension. Therefore predicting the presence of varices by ascitic fluid examination may be helpful.

Aim of Study: To study the correlation between SAAG and presence and grades of esophageal varices in $C L D$.

Result: A total of 51 patients were studied which included 29 Alcoholic and 22 non Alcoholic CLD. These patients were devided into 3 groups - Group A with SAAG = 1.1-1.49 (6 patients), Group B with SAAG= 1.5-1.99 (21 patients) and Group $C$ with $S A A G>2.0$ (24 patients). In group A, 33\% patient had varices, In group $B, 76.1 \%$ had varices while in group $C$ all the 24 patients $(100 \%)$ had varices $(p<0.05)$. Among alcoholic 26 out of 29 patients had varices while among non-alcoholic 16 out of 22 patients had varices $(Z=1.70)$.

Conclusion: We concluded in our study that there was significant correlation between SAAG value and endoscopic parameter of portal hypertension manifested by presence of varices. But the SAAG value has no significant correlation with severity of varices. This correlation exist in both alcoholic as well nonalcoholic liver disease, though there is proportionate difference among both these group and correlation is weaker in non-alcoholic liver disease.
\end{abstract}

Keywords: SAAG, Portal Hypertension, Esophageal Varices, CLD, Liver cirrhosis. 


\section{INTRODUCTION}

Ascites is pathological accumulation of excess fluid in the peritoneal cavity due to a combination of abnormally in renal function and portal and splanchnic circulation. More than $90 \%$ of cases are caused by liver cirrhosis (most common), neoplasm, congestive cardiac failure and tuberculosis. Previously ascites was classified into transudative and exudative type which is obsolete now since the introduction of concept of serum ascites albumin concentration gradient (SAAG). SAAG is calculated by measuring the albumin concentration of ascitic fluid and subtracting it from serum value of albumin obtained at the same time. On the basis of value of SAAG, ascites is classified as high gradient $(\geq 1.1 \mathrm{~g} / \mathrm{dL})$ and low gradient $(<1.1 \mathrm{~g} / \mathrm{dL})^{1,2}$. Various studies has proved that $\mathrm{SAAG}$ value $\geq 1.1 \mathrm{~g} / \mathrm{dl}$, is related with portal hypertension. ${ }^{3,4}$

Portal hypertension is defined as portal vein pressure $>10 \mathrm{mmHg}$ (normal PVP being 5-10 $\mathrm{mmHg})^{5}$. This increased pressure results from a functional obstruction to blood flow from any point in the portal system origin (in the splanchnic bed) through the hepatic veins (exit into systemic circulation) or from an increase in blood flow in the system. Clinically significant portal hypertension is present in $>60 \%$ of patient with cirrhosis. Portal hypertension results from an interaction of abnormal intrahepatic resistance and increases in portal blood flow. The end result of these interactions is the development of increased portal pressure and portosystemic collaterals, the most important of which are esophageal varices. The rupture of esophageal varices is a devastating complication of portal hypertension. Variceal wall tension is the best single descriptor of risk from variceal hemorrhage ${ }^{6}$. Portal hypertension is contributing mechanism for the development of ascites and encephalopathy, and a direct cause for variceal bleeding. Variceal bleeding being most dramatic complication in gastroenterology with high mortality rate needs early detection in patients of CLD. Portal pressure was first measured intraoperatively in 1936 by Rousselot ${ }^{7}$ and by Thompson in $1937^{8}$. Hepatic vein catheterization was first developed in 1940 and lead to indirect method for measuring portal pressure by outflow occlusion ${ }^{9}$.Ideally portal hypertension should be evaluated by actually measuring portal pressure. Hepatic vein pressure gradient measurement is a safe and reproducible procedure. But it is invasive procedure and involves catheterization of hepatic vein not applicable on a routine basis, therefore alternate method may be useful.

Upper GI endoscopy has diagnostic as well as therapeutic utility in determining esophageal varices and variceal bleed. By upper GI endoscopy presence of varices, variceal size and grading of varices is clearly determined with satisfactory degree of accuracy. Screening of the patients with CLD for the presence of esophageal varices is important because detection of varices is helpful for providing the prophylactic therapy to reduce the complication which is hazardous.

Ascites and esophageal varices both being a complication of portal hypertension has definite correlation. Therefore predicting the presence of varices by ascitic fluid examination may be helpful and cost effective . 'Platelet count/spleen diameter ratio' has also been suggested as noninvasive parameter to predict the presence of oesophageal varices in patients with liver cirrhosis $^{10}$.

\section{AIM OF STUDY}

To study the correlation between SAAG and presence and grades of esophageal varices in CLD.

\section{MATERIAL AND METHOD}

In this study we included adult patients of Chronic liver disease whether alcoholic or non-alcoholic presenting with ascites. Following patients were excluded from the study - Patients with Hepatic encephalopathy, active upper GI bleeding, CHF , Nephrotic syndrome, Protein loosing enteropathy, patients with hepatic or extrahepatic metastasis, Other conditions with high SAAG (Budd chiarry 
syndrome, Portal Vein thrombosis, Spleenic vein thrombosis), Patients with evidence of peritonitis i.e. Tubercular peritonitis, secondary bacterial peritonitis

\section{METHOD}

All selected patients were evaluated for CBC, S.LFT , Viral marker ( HbsAg, Anti HCV), USG Abdomen and upper GI Endoscopy. Patients were devided into two groups - alcoholic and nonalcoholic. Criteria for alcoholic was based on History of alcohol intake i.e. Intake of $>60-80$ $\mathrm{g}$ /day of alcohol for 10 years for men and $>20-40$ $\mathrm{g}$ /day of alcohol for 10 years for females. Diagnostic paracentesis was done for Ascitic fluid examination. SAAG value was calculated by subtracting ascitic fluid albumin from serum albumin level. On the basis of SAAG value patients were devided into three groups with SAAG 1.1-1.49 , 1.5-1.99 and >2.0. Upper GI Endoscopy of all patients done to determine the presence and grade of varices. Paquet's Grading ${ }^{11}$ used for grading of varices : Grade I - Varices without luminal prolapsed, Grade II -Moderate sized varix showing luminal prolapse with minimal obscuring of the GE Junction, Grade III Large varix showing luminal prolapse substantially obscuring the GE Juntion, Grade IV -Very large varix completely obscuring the GE Junction.

All statistical analysis were done using paired $t$ test and Chi square test and Fisher's z test.

\section{RESULTS}

A total of 51 patients were studied which included 29 Alcoholic and 22 non Alcoholic CLD. Mean age of the patients was $45.39 \pm 11.56$. Among these 42 were male $(82.3 \%)$ and 9 were females $(17.6 \%)$.The lowest age was 21 years and highest age was 70 years. According to SAAG value patients were categorized into 3 groups. Group A with SAAG = 1.1-1.49 included 6 patients (mean $1.36 \pm 0.07)$ of which 4 were alcoholic and 2 were non-alcoholic. Group B with SAAG $=1.5-1.99$ included 21 patients (mean $1.67 \pm 0.11$ ) of which 12 were alcoholic and 9 were non-alcoholic. Group C (SAAG > 2.0) included 24 patients (mean 2.16 \pm 0.13 ) of which 13 were alcoholic and 11 non-alcoholic (Table 1)

Table 1: Distribution of Patients according to SAAG value

\begin{tabular}{|l|l|l|l|}
\hline SAAG value & Total patients & Alcoholic & $\begin{array}{l}\text { Non- } \\
\text { Alcoholic }\end{array}$ \\
\hline $1.1-1.49$ & 06 & 04 & 02 \\
\hline $1.50-1.99$ & 21 & 12 & 09 \\
\hline$>2.0$ & 24 & 13 & 11 \\
\hline & 51 & 29 & 22 \\
\hline
\end{tabular}

In group A 2 of the 6 patients (33\%) have varices. In group B 16 of the 21 patients $(76.1 \%)$ have varices while in group $\mathrm{C}$ all the 24 patients $(100 \%)$ had varices $(\mathrm{P}<0.05)$. There was significant correlation between SAAG value and presence of varices. This correlation was significant in both Alcoholic and non alcoholic (P $<0.05)$. ( Table 2 ) 
Table 2: Distribution of patients according to presence of varices and SAAG value

\begin{tabular}{|l|l|l|l|}
\hline SAAG value & Total patients & Varices & No varices \\
\hline $1.1-1.49$ & 06 & 02 & 04 \\
\hline $1.50-1.99$ & 21 & 16 & 05 \\
\hline$>2.0$ & 24 & 24 & 00 \\
\hline & 51 & 42 & 09 \\
\hline
\end{tabular}

Among alcoholic 26 out of 29 patients had varices while among non- alcoholic 16 out of 22 patients had varices $(Z=1.70)$. So there was significant proportional difference among alcoholic and non alcoholic.
There was no correlation between SAAG value and Grading of varices( $\mathrm{P}>0.05)$.

Table 3: Distribution of patients according to SAAG value and grading of varices

\begin{tabular}{|l|l|l|l|}
\hline Grades of varices & \multicolumn{3}{|l|}{ SAAG value } \\
\cline { 2 - 4 } & $1.1-1.49$ & $1.5-1.99$ & $>\mathbf{2 . 0}$ \\
\hline Grade 1 & 1 & 3 & 0 \\
\hline Grade 2 & 1 & 8 & 12 \\
\hline Grade 3 & 0 & 5 & 12 \\
\hline Grade 4 & 0 & 0 & 0 \\
\hline
\end{tabular}

\section{DISCUSSION}

Hoefs et al and Rector et al in their studies have shown that an excellent correlation exist between portal hypertension and SAAG among alcoholic CLD ${ }^{12,3}$. Contrary to this Kajani et $a^{13}$ studied this correlation between patients with alcoholic cirrhosis and cirrhosis due to causes other than alcoholic cirrhosis. In this study a correlation was found between SAAG and either portal pressure $(\mathrm{r}$ $=0.02)$ or esophageal varices $(r=0.53)$ in alcoholic patients. But in patients with non alcoholic cirrhosis, no correlation was found between SAAG and portal pressure $(r=0.39)$, while correlation between SAAG and varices was found to be weaker $(r=0.02)$. This finding was similar to study of Al Knaway et $\mathrm{al}^{14}$ in which 5 patients of liver disease had SAAG $<1.1 \mathrm{~g} / \mathrm{dl}$ despite the presence of esophageal varices by endoscopy, which indicates the presence of portal hypertension. Torres et $\mathrm{al}^{15}$ in there study found that presence of EV in patients with ascites and high SAAG was directly related to the degree of SAAG. The size of the EV in patients with ascites and high SAAG was not associated with the degree of SAAG. A SAAG value of $>$ or $=1.435$ $+/-0.015 \mathrm{~g} / \mathrm{dl}$ was determined a useful means to predict the presence of $\mathrm{EV}$ in patients with ascites and EV were more prevalent in those with ALD. Gurubacharya DL et $\mathrm{al}^{16}$ found the similar result in their study as shown by Torres et al. Study by Demirel $\mathrm{U}^{17}$ et al supported the observation that SAAG value increases in ascites due to portal hypertension, but there is no close correlation between severity of esophageal varices and SAAG value. It was remarkable that all the patients with SAAG value $>2$ had esophageal varices.

In our study we found significant correlation between SAAG value and presence of varices $(p$ value $<0.05$ ). We also found that all the patients with SAAG value $>2.0$ had varices. Thus our 
study supports the findings of Torres et al, Demirel $U$ et al as well as Rector et al that SAAG value and presence of varices has significant correlation. There was significant correlation between SAAG and presence of varices among both alcoholic as well as non alcoholic CLD ( $p$ value $<0.05$ ), though there was significant proportionate difference among both groups. We found no correlation between SAAG value and grading of varices ( $\mathrm{p}$ value $>0.05$ ) similar to Efrain $\mathrm{T}$ et $\mathrm{al}^{18}$ and Demirel $\mathrm{U}$ et al.

Torres et al proposed that a SAAG value of $>$ or $=1.435+/-0.015 \mathrm{~g} / \mathrm{dl}$ is a useful means to predict the presence of EV in patients with ascites. Goran Bjelakovic $^{19}$ proposed new cut off value of SAAG for discriminating the patients with and without portal hypertension of $1.60 \mathrm{~g} / \mathrm{dl}$. This had high sensitivity and specificity. While Demirel U et all proposed that all the patients with SAAG value > 2.0 had varices. In our study we found that predicting the presence of esophageal varices on the basis of SAAG value > 1.5 have sensitivity of $95.2 \%$ and specificity is $44.4 \%$. The positive predictive value is $88.8 \%$ and negative predictive value is $66.6 \%$. While applying the results of our study with the SAAG value of $>2.0$ as cut off point have sensitivity $57 \%$ and specificity is 100 $\%$, positive predictive value is $100 \%$ and negative predictive value is $33 \%$. The conclusion is that prediction of varices by cut off value of SAAG > $2.0($ mean $=2.16 \pm 0.13)$ is highly specific but less sensitive while applying SAAG value $>1.5$ (mean $1.67 \pm 0.11$ ) has high sensitivity but low specificity.

\section{CONCLUSION}

We concluded in our study that there is significant correlation between SAAG value and endoscopic parameter of portal hypertension manifested by presence of varices. But the SAAG value has no significant correlation with severity of varices. This correlation exist in both alcoholic as well non- alcoholic liver disease, though there is proportionate difference among both these group and correlation is weaker in non-alcoholic liver disease.
Presence of varices can be predicted by using SAAG value as screening test. Cut off value of SAAG $>1.5$ has high sensitivity while SAAG value $>2.0$ has high specificity. Screening of the patients for presence of varices by ascitic fluid examination is cost effective, easy to perform and may avoid unnecessary burden over endoscopy unit and can be a useful option in peripheral centres where endoscopy facility is still not available.

\section{REFERENCES}

1. Runyon BA, Montano AA, Akriviadis EA, Antillon MR, Irving MA, McHutchison $\mathrm{JG}$, The serum-ascites albumin gradient is superior to the exudate-transudate concept in the differential diagnosis of ascites. Ann Intern Med. 1992 Aug 1;117(3):215-20.

2. Akriviadis EA, Kapnias D, Hadjigavriel M, Mitsiou A, Goulis J, Serum/ascites albumin gradient: its value as a rational approach to the differential diagnosis of ascites, Scand J Gastroenterol. 1996 Aug;31(8):814-7.

3. Rector WG Jr., Reynolds TB, Superiority of the serum-ascites albumin difference over ascites total protein concentration in separation of "transudative" and "exudative" ascites, Am J Med 1984;47:83-85.

4. Alba D, Torres E, Vázquez JJ, Sero-ascitic gradient of albumin: usefulness and diagnostic limitations, An Med Interna. 1995 Aug;12(8):404-7.

5. S.Wongcharatrawee, and R.GroszmannHemodynamic assessment in clinical practice in portal hypertensive cirrhotics, ANNALS OF GASTROENTEROLOGY 2001, 14(3):158-165

6. MacMathuna PM: Mechanisms and consequences of portal hypertension, Drugs. 1992;44 Suppl 2:1-13; discussion 70-2.

7. Rousselot LM. The role of congestion (portal hypertension) in so called Banti's 
syndrome: a clinical and pathological study of thirty one cases with late results follwing spleenectomy, J Am Med assoc 1936;107:1788-1793.

8. Thompson WP, Caughey JL, Whipple AO, Rousselot LM, Spleenic vein pressure in congestive spleenomegaly (Banti's syndrome). J Clin Invest 1937;16:571-572.

9. Friedman EW, Weisner RS, Estimation of hepatic sinuside pressure by means of venous catheter and estimation of portal pressure by hepatic vein catheterization, Am J Physiol 1951; 165;527-531.

10. Giannini E, Botta F, Borro P, Risso D, Romagnoli P, Fasoli A, Mele MR, Testa E, Mansi C, Savarino V, Testa R, Platelet count/spleen diameter ratio: proposal and validation of a non-invasive parameter to predict the presence of oesophageal varices in patients with liver cirrhosis, Gut. 2003 Aug;52(8):1200-5.

11. Paquet KJ, Prophylactic endoscopic sclerosing treatment of esophageal wall in varices: A prospective controlled trial, Endoscopy. 1982;14:4-5 [PubMed]

12. Hoefs JC, Serum protein concentration and portal pressure determine the ascitic fluid protein concentration in patients with chronic liver disease. J Lab Clin Med 1983;102:260-273.

13. Kajani MA, Yoo YK, Alexander JA, Gavaler JS, Stauber RE, Dindzans VJ, Van Thiel DH: Serum-ascites albumin gradients in nonalcoholic liver disease. Dig Dis Sci. 1990 Jan;35(1):33-7.

14. Al-Knawy BA. Etiology of ascites and the diagnostic value of serum-ascites albumin gradient in non-alcohol liver disease. Ann Saudi Med 1997;17:26-28.

15. Torres E, Barros P, Calmet F: Correlation between serum-ascites albumin concentration gradient and endoscopic parameters of portal hypertension. Am J Gastroenterol. 1998 Nov;93(11):2172-8.

16. Gurubacharya DL, Mathura KC, Karki DB, Correlation between serum-ascites albumin concentration gradient and endoscopic parameters of portal hypertension, Kathmandu Univ Med J (KUMJ). 2005 Oct-Dec;3(4):327-33.

17. Demirel U, Karincaoglu M, Harputluoglu M, Ateş M, Seçkin Y, Yildirim B, Hilmioglu F, Two findings of portal hypertension: Evaluation of correlation between serum-ascites albumin gradient and esophageal varices in non-alcoholic cirrhosis, Turk J Gastroenterol. 2003 Dec;14(4):219-22.

18. Efrain T, Pedro B, Fernando C, Correlation between serum ascites albumin concentration gradient and endoscopic parameter of portal hypertension, Am J Gastroenterology. 1998; 93 (11): 21722178.

19. Goran Bjelakovic, Aleksandar Nagorni , Ivanka Stamenkovic, Daniela BenedetoStojanov, Vesna Brzacki, Suzana Raicevic, Biljana Radovanovic, Marija Bjelakovic, Vuka Katic, Vesna Zivkovic, Dragomir Vucetic, The value of Serum Ascites albumin gradient in differential diagnosis of ascites and the proposal for the new cut off Value, ACTA FAC. MED. NAISS. 2003; 20 (4): 209-212. 